\title{
Development of a kojic monooleate-enriched oil-in-water nanoemulsion as a potential carrier for hyperpigmentation treatment
}

This article was published in the following Dove Press journal: International Journal of Nanomedicine

\author{
Sharifah Nurfadhlin Afifah \\ Syed Azhar \\ Siti Efliza Ashari \\ Norazlinaliza Salim \\ Integrated Chemical BioPhysics \\ Research, Faculty of Science, \\ Universiti Putra Malaysia, Serdang, \\ Selangor, Malaysia
}

\begin{abstract}
Introduction: Kojic monooleate (KMO) is an ester derived from a fungal metabolite of kojic acid with monounsaturated fatty acid, oleic acid, which contains tyrosinase inhibitor to treat skin disorders such as hyperpigmentation. In this study, KMO was formulated in an oil-in-water nanoemulsion as a carrier for better penetration into the skin.

Methods: The nanoemulsion was prepared by using high and low energy emulsification technique. D-optimal mixture experimental design was generated as a tool for optimizing the composition of nanoemulsions suitable for topical delivery systems. Effects of formulation variables including KMO $(2.0 \%-10.0 \% \mathrm{w} / \mathrm{w})$, mixture of castor oil (CO):lemon essential oil (LO; 9:1) $(1.0 \%-5.0 \% \mathrm{w} / \mathrm{w})$, Tween $80(1.0 \%-4.0 \% \mathrm{w} / \mathrm{w})$, xanthan gum $(0.5 \%-1.5 \% \mathrm{w} / \mathrm{w})$, and deionized water $(78.8 \%-94.8 \% \mathrm{w} / \mathrm{w})$, on droplet size as a response were determined.

Results: Analysis of variance showed that the fitness of the quadratic polynomial fits the experimental data with $F$-value $(2,479.87)$, a low $P$-value $(P<0.0001)$, and a nonsignificant lack of fit. The optimized formulation of KMO-enriched nanoemulsion with desirable criteria was $\mathrm{KMO}(10.0 \%$ w/w), Tween $80(3.19 \% \mathrm{w} / \mathrm{w}), \mathrm{CO}: \mathrm{LO}(3.74 \% \mathrm{w} / \mathrm{w})$, xanthan gum $(0.70 \% \mathrm{w} / \mathrm{w})$, and deionized water $(81.68 \% \mathrm{w} / \mathrm{w})$. This optimum formulation showed good agreement between the actual droplet size $(110.01 \mathrm{~nm})$ and the predicted droplet size $(111.73 \mathrm{~nm})$ with a residual standard error $<2.0 \%$. The optimized formulation with $\mathrm{pH}$ values (6.28) showed high conductivity $\left(1,492.00 \mu \mathrm{Scm}^{-1}\right)$ and remained stable under accelerated stability study during storage at $4{ }^{\circ} \mathrm{C}, 25^{\circ} \mathrm{C}$, and $45^{\circ} \mathrm{C}$ for 90 days, centrifugal force as well as freeze-thaw cycles. Rheology measurement justified that the optimized formulation was more elastic (shear thinning and pseudo-plastic properties) rather than demonstrating viscous characteristics. In vitro cytotoxicity of the optimized KMO formulation and $\mathrm{KMO}$ oil showed that $\mathrm{IC}_{50}(50 \%$ inhibition of cell viability) value was $>100 \mu \mathrm{g} / \mathrm{mL}$.

Conclusion: The survival rate of $3 \mathrm{~T} 3$ cell on KMO formulation $(54.76 \%)$ was found to be higher compared to KMO oil (53.37\%) without any toxicity sign. This proved that the KMO formulation was less toxic and can be applied for cosmeceutical applications.
\end{abstract}

Keywords: kojic monooleate, anti-tyrosinase, hyperpigmentation, nano-cosmeceutical, D-optimal mixture experimental design

\section{Introduction}

Hyperpigmentation is a skin disorder with excessive production of skin color pigment called melanin within the skin layer of epidermis, dermis, or both. This skin disorder may occur congenitally or inherently. Also, excessive exposure of harmful ultraviolet light and intake of certain drugs or chemicals may as well contribute to the skin condition. ${ }^{1}$ Numerous skin lightening agents available over the counter may be skin irritants and may require an extended period before the claimed results appear; also, some products
Correspondence: Siti Efliza Ashar Integrated Chemical BioPhysics Research, Faculty of Science, Universiti Putra Malaysia, 43400, Serdang, Selangor, Malaysia

Tel +6038947 7847

Email ctefliza@upm.edu.my 
are only partially effective. Hydroquinone, a well-known compound that inhibits tyrosinase activity with skin bleaching effect, is one of the lightening agents that causes more skin irritation and contact dermatitis which can only be cured by topical steroids. It has been reported that a rare side effect of using hydroquinone is the development of exogenous ochronosis, sooty hyperpigmentation in the treatment area, which is difficult to cure. ${ }^{2}$ Therefore, to overcome these problems, cosmeceutical industries are likely to seek an alternative using natural and safer ingredients for production.

Kojic acid (KA) ester, derived from KA (production of a fungal metabolite from species of Aspergillus, Acetobacter, and Penicillium), acts as a tyrosinase inhibitor to treat overproduction of melanin in the human skin. ${ }^{3}$ As enzymatic esterification technique using fatty acid has been revealed to be the best approach to produce KA ester, the esters are also excellent in quality than the original starting material (KA) making them more advantageous in terms of cosmetic purposes. ${ }^{4} \mathrm{Kim}$ et al showed that KA ester has excellent storage stability and is less toxic as compared to KA. ${ }^{5}$ Moreover, KA derivatives proved that more activities of tyrosinase inhibition were performed rather than that of KA. Kojic monooleate (KMO), a palm-based fatty acid derivative of KA was found to have significantly superior tyrosinase inhibition activities than kojic monolaurate and kojic monopalmitate. The tyrosinase inhibition activity effect of KMO was not very different to KA at doses ranging from 62.5 to $250 \mu \mathrm{g} / \mathrm{mL}$. ${ }^{6}$ This proves that $\mathrm{KMO}$ can be used as an active ingredient for tyrosinase-related skin problems such as hyperpigmentation.

Nanotechnology concepts have been used in dermatology for years. The carrier system helps to load the active ingredients to the targeted area efficiently. The nanoemulsion is a carrier system which consists of oil and water stabilized by a surfactant produced by high or low or both energy emulsification. It is considered to be the most advanced nanoparticulate system for cosmeceutical uses because it involves submicron sizes ranging from 20 to $200 \mathrm{~nm}$ which can penetrate into deep skin cells easily. ${ }^{7}$ The uniqueness of nanoemulsions that resist physical destabilization due to aggregation and gravitational separation can improve the potent activity of the nanoemulsion especially toward antimicrobial activity. ${ }^{8}$ To enhance permeation of the active ingredients into the skin, an oil-in-water $(\mathrm{O} / \mathrm{W})$ nanoemulsion was used as a potential carrier system and proved to be better than a water-in-oil (W/O) nanoemulsion for topical delivery systems because $\mathrm{O} / \mathrm{W}$ ensures better penetration into the skin, increased the effectiveness to deliver the active ingredient, and contains counter ions that could be applied to optimize targeting active compounds without a concomitant increase in systemic absorption. ${ }^{9}$ Pre-formulation of mixture composition is one of the important aspects to obtain satisfactory and desirable products for cosmeceuticals purposes.

Therefore, a mathematical approach using D-optimal mixture experimental design (MED) is favorable for determining the optimum mixture composition and to study the relationship between variables. This systematic and scientific method not only improves the traditional method but also could develop a method for characterizing formulations and process. As reported by Borhan et al, this model has been widely implemented in industries such as food, pharmaceutical, and cosmeceutical sectors. ${ }^{10}$ This approach saves time and requires less energy whereby the experimental run can be reduced. There have been no studies reported on the optimization of KMO-enriched O/W nanoemulsion using D-optimal MED yet and only some research has been reported using this mathematical approach for cosmeceutical applications. Thus, in this study, D-optimal MED was utilized for optimizing the composition of KMO-enriched $\mathrm{O} / \mathrm{W}$ nanoemulsion and to study the interaction variables (surfactant, oils, KMO, xanthan gum, and deionized water) against response (droplet size). Furthermore, the optimized nanoemulsion, which potentially can be used as a carrier for hyperpigmentation treatment, was then characterized for its physicochemical properties.

\section{Materials and methods Materials}

$\mathrm{KMO}$ was obtained according to the method used by Jumbri et al. ${ }^{11}$ Virgin coconut oil (VCO, from Cocos nucifera), soybean oil (SO), safflower seed oil (SSO), castor oil (CO), xanthan gum (from Xanthomonas campestris), and potassium sorbate were purchased from Sigma-Aldrich (St Louis, MO, USA). Palm kernel oil ester (PKOE) was obtained according to the method used by Keng et al. ${ }^{12}$ Lemon essential oil (LO) South African was purchased from Wellness Original Ingredient (Puchong, Malaysia), whereas polyoxyethylene sorbitan monooleate and Tween 80 (hydrophile-lipophile balance [HLB] 15.0) were purchased from EMD Millipore (Billerica, MA, USA). Deionized water was purified using a Milli-Q water system (EMD Millipore). The $3 T 3$ cell lines (from mouse embryonic fibroblast cells) were purchased commercially from American Type Culture Collection (Manassas, VA, USA). Chemicals used were all analytical, food, or cosmetic grade classes.

\section{Solubility determination of $\mathrm{KMO}$ in oil}

The solubility of KMO $(3 \% \mathrm{w} / \mathrm{w})$ in five different types of oil (VCO, PKOE, SO, SSO, and CO) was investigated. To increase the solubility, LO was added to the selected oil 
in the ratio 1:9. The total volume was $5 \mathrm{~mL}$. The mixture was vortexed (VTX-3000L Mixer Uzusio; LMS, Tokyo, Japan) for 5 minutes to reach equilibrium and then centrifuged (EBA 200; Hettich Zentrifugen, Tuttlingen, Germany) at 4,000 rpm for 15 minutes. Phase separation was observed and recorded.

\section{Preparation of $\mathrm{KMO} \mathrm{O} / \mathrm{W}$ nanoemulsion}

The nanoemulsion was prepared using both high and low energy emulsification techniques. The oils used were a mixture of $\mathrm{CO}$ and $\mathrm{LO}$ in the ratio of 9:1. CO was chosen to be used as a carrier oil to blend with LO for better enhancement of nanoemulsion. A nonionic surfactant (Tween80) was selected to acquire better solubilization and stability of the dispersion system developed. Thus, due to its suitable HLB value, it was chosen as an $\mathrm{O} / \mathrm{W}$ emulsifier. The oil phase was obtained by blending $\mathrm{KMO}$ and $\mathrm{CO}$, while in the aqueous phase Tween 80 and xanthan gum were added to the deionized water. Both oil and aqueous phases were separately heated up to $30^{\circ} \mathrm{C}$ with continuous stirring using a magnetic stirrer to form a homogenous solution. Then, both phases were separately sonicated using an ultrasonic bath sonicator (Power Sonic 405, Hwashin Technology Co., Seoul, Korea) where it cavitated bubbles induced by high frequency pressure (sound) waves to agitate a liquid for 20 minutes. Using a high shear homogenizer (T25 digital; IKA-Werk, GmbH \& Co. KG, Staufen im Breisgau, Germany), the oil phase was gradually added dropwise into the aqueous phase until completion for 15 minutes at 6,000 rpm. The final mixture was further homogenized for 3 hours while adding $\mathrm{LO}$ and $0.7 \% \mathrm{w} / \mathrm{w}$ of potassium sorbate dropwise using an overhead stirrer (RW20 digital; IKA-Werk) at $250 \mathrm{rpm}$.

\section{Experimental design}

The composition of a mixture is an important aspect in D-optimal mixture design. Five factors were utilized to study the composition effect of Tween80 (A), CO:LO with a ratio of 9:1 (B), KMO (C), xanthan gum (D), and deionized water $(\mathrm{E})$ on the response considered to be the droplet size. Potassium sorbate (antimicrobial agent) was kept constant at $0.7 \% \mathrm{w} / \mathrm{w}$. Table 1 demonstrates the constraints of the independent variables proportions.

Table I Constraints of independent variables proportions

\begin{tabular}{lll}
\hline $\begin{array}{l}\text { Independent } \\
\text { variables, } \boldsymbol{X}_{j}\end{array}$ & $\begin{array}{l}\text { Lower } \\
\text { limit, } \boldsymbol{L}_{j}\end{array}$ & $\begin{array}{l}\text { Upper } \\
\text { limit, } \boldsymbol{U}_{j}\end{array}$ \\
\hline Tween 80, A & 1.0 & 4.0 \\
CO:LO, B & 1.0 & 5.0 \\
KMO, C & 2.0 & 10.0 \\
Xanthan gum, D & 0.5 & 1.5 \\
Deionized water, E & 78.8 & 94.8 \\
\hline
\end{tabular}

Notes: The letters A-E represent the independent variables, where $A$ is Tween 80 , $B$ is CO:LO, C is KMO, D is xanthan gum, and $E$ is deionized water.

Abbreviations: CO, castor oil; LO, lemon essential oil; KMO, kojic monooleate.
The design matrix was developed using Design Expert software (version 7.1.5; Stat Ease Inc., Minneapolis, MN, USA). Based on the mixture design, the input variables were nonnegative proportionate amounts of the mixture where the sum had to be equal to 1 .

There were restrictions on the component $X_{j}$, with general form as in Equation 1:

$$
\Sigma X_{j}=1 \text { and } L_{j} \leq X_{j} \geq U_{j}
$$

The lower $\left(L_{j}\right)$ and upper $\left(U_{j}\right)$ constraints were restricted to prevent the experimenter from analyzing the entire simplex region. Furthermore, the response had to depend only on the relative proportions of the composition in the mixture and not the volume of the mixture. ${ }^{38}$

A total of 24 runs was developed and the results were statistically evaluated. Randomized order of composition of each run was implemented to minimize the unexplained variability in the actual response.

\section{Statistical analysis}

Optimum compositions of the nanoemulsion were selected upon the condition resulting in minimum droplet size. The goodness of fit of analysis of variance (ANOVA) and coefficient of determination $\left(R^{2}\right)$ were determined to study the significant differences among the independent variables in terms of lack-of-fit test. The best final reduced model can be achieved with probability value ( $P$-value) that is significant $(P<0.05)$.

\section{Verification of models}

Verification of the final model was carried out to study the adequacy of the predicted response values in the validation set. In order to validate the model, some random formulations with different percentages of composition were considered. The actual and predicted response values as well as percentage of the residual standard error (RSE) were calculated. The final optimum composition suggested was also used to confirm the predicted optimum values from the model.

\section{Physicochemical characterization Droplet size, zeta potential, and polydispersity index (PDI) determination}

Dynamic light scattering method was used to measure the droplet size, stability, and size distribution of molecules in the nanoemulsions system using a droplet size analyzer (Zetasizer Nano ZS90; Malvern Instruments, Malvern, $\mathrm{UK}$ ), scattered at an angle of $173^{\circ}$ (temperature $25^{\circ} \mathrm{C}$ ). The required concentration of samples was obtained using 
dilution with deionized water to reduce multiple scattering effects before being filled into a folded capillary cell (DTS1070; Malvern Instruments). The count rate was kept between 100 and $300 \mathrm{kcps}$. The droplet size (20-200 nm) was analyzed based on the intensity weighted distribution ( $Z$-average), while the zeta potential was determined based on the measurement of the electrophoretic mobility of dispersed particles in a charged field. All measurements were repeated three times and the values were reported as mean values.

\section{Transmission electron microscopy (TEM) measurement}

The size and morphology of the optimized nanoemulsion were investigated using microscopy technique by TEM (JEOL JEM-1400Flash; JEOL, Tokyo, Japan). The sample was homogenized in deionized water. A formvar coated copper grid was arranged on top of a drop of diluted sample and left at room temperature $\left(25^{\circ} \mathrm{C}\right)$ for 3 minutes. It was then stained using $2 \%$ phosphotungstic acid for 2 minutes and air dried before analysis.

\section{$\mathrm{pH}$ and conductivity measurement}

The $\mathrm{pH}$ and conductivity of the optimized nanoemulsion were determined using a Delta $320 \mathrm{pH}$ meter (Mettler Toledo, Columbus, OH, USA) and a conductometer (Mettler Toledo), respectively. Calibration with three $\mathrm{pH}$ standard buffer solutions ( $\mathrm{pH} 4.00,7.00$, and 10.00) was performed before $\mathrm{pH}$ measurements were taken. The $\mathrm{pH}$ measurement is crucial to check the compatibility of a sample with human skin. Conductivity value determines the number of free ions in the system. High conductivity indicates that the aqueous phase is the continuous phase of the system. Therefore, the type of nanoemulsion can be investigated as either $\mathrm{O} / \mathrm{W}$ or vice versa.

\section{Rheological behavior study}

Viscosity of the optimized nanoemulsion was studied by using an AR-G2 rheometer (TA Instruments, New Castle, DE, USA). The measurement was carried out with $4^{\circ} \mathrm{C} / 40 \mathrm{~mm}$ cone and plate geometries (gap of $0.100 \mathrm{~mm}$ ) at $25^{\circ} \mathrm{C}$. The steady rheological behavior of the sample was analyzed at a controlled rate varying from 0.1 to $100 \mathrm{~s}^{-1}$. Before measurements were taken, the sample was allowed to stand for 10 minutes after being loaded to achieve an equilibrium state. The experimental data were fitted to the power law model as in Equation 2:

$$
\eta=k \grave{y}^{n-1}
$$

where $\eta$ is the viscosity (Pa.s), ỳ is the shear rate $\left(\mathrm{s}^{-1}\right)$, and $k$ and $n$ are the consistency index and flow behavior index, respectively.

The viscoelastic characteristics of the optimized nanoemulsion were studied using oscillatory strain sweep analysis at different strain amplitudes $(1 \%-1,000 \%)$ at a fixed frequency $(1 \mathrm{~Hz})$. This study was implemented to determine the storage $\left(\mathrm{G}^{\prime}\right)$ and loss $\left(\mathrm{G}^{\prime \prime}\right)$ modulus for a linear viscoelastic region (LVR).

\section{Accelerated stability study}

The stability study of the optimized nanoemulsion involved the following: 1) stability under centrifugation, 2) freezethaw cycles tests, and 3 ) thermal stability under storage for 90 days (at room temperature; $25^{\circ} \mathrm{C}, 45^{\circ} \mathrm{C}$, and $4^{\circ} \mathrm{C}$ ). For stability under centrifugation, the sample was subjected to a centrifugal force for 15 minutes at 4,000 rpm. Stability of the sample was observed. In the freeze-thaw cycle test, the sample was kept in a vial and frozen in the refrigerator at $4^{\circ} \mathrm{C}$ for 24 hours. Then, the sample was thawed at room temperature for another 24 hours. These steps were repeated for five cycles (10 days). Phase changes of the sample were observed for each cycle. Three analyses, coalescence rate, Ostwald ripening, and freeze-thaw cycle, were performed for better interpretation of the stability of the optimized nanoemulsion.

The coalescence rate analysis was carried out to determine the factor that effects the changes of droplet size over time. All the collected droplet size data within the three different storage temperatures were analyzed as in Equation 3:

$$
\frac{1}{r^{2}}=\frac{1}{r_{0}^{2}}-\left(\frac{8 \pi}{3}\right) \omega t
$$

In this equation, $r$ is the mean radius after a certain time, $\omega$ is the frequency of rupture per unit of the film surface, and $r_{0}$ the value at time $t=0$. A graph of $\left(1 / r^{2}\right)$ against time (seconds) was plotted to evaluate the coalescence rate. A linear relationship pattern was predicted for the coalescence rate.

The enlargement of nanoemulsion droplet size due to the diffusion of the oil phase through the aqueous phase is the effect of Ostwald ripening. Based on the LifshitzSlesov-Wagner theory, the effect of storage temperature due to the Ostwald ripening of all samples can be determined. Equation 4 shows the calculation used in the Ostwald ripening study:

$$
\omega=\frac{d r^{3}}{d t}=\frac{8}{9}\left[\frac{C(\infty) \gamma V_{m} D}{\rho R T}\right]
$$


where $\omega$ is the frequency of rupture per unit surface of the film, $r$ is the average radius of the droplets over time, $t$ is the storage time in seconds, $C(\infty)$ is the bulk phase solubility, $V_{m}$ is the molar volume of the internal phase, $D$ is the diffusion coefficient of the dispersed phase in the continuous phase, $\rho$ is the density of the dispersed phase, $R$ is the gas constant, and $T$ is the absolute temperature. Graphs of radii $\left(\mathrm{nm}^{3}\right)$ against storage time (seconds) at three different storage temperatures were plotted and analyzed.

\section{Thermogravimetric analysis (TGA) determination}

TGA/SDTA851 (Mettler Toledo) was used to determine the thermal properties of the optimized nanoemulsion. This technique is used for measuring changes in the mass of the nanoemulsion that occur in response to temperatures ranging from $50^{\circ} \mathrm{C}$ to $600^{\circ} \mathrm{C}$. Liquid nitrogen was used as a gas carrier in the system. The sample was then loaded into the instrument in the aluminum pan and the empty pan was set as a reference.

\section{In vitro cytotoxicity assay}

Cytotoxicity activity of the optimized KMO-enriched O/W nanoemulsion was tested using 3-(4,5-dimethylthiazol2-yl)-2,5-diphenyltetrazolium bromide (MTT) assay on the $3 \mathrm{~T} 3$ cell of mouse embryonic fibroblast cells. Cell culture with a concentration of $2 \times 10^{3}$ cells $/ \mathrm{mL}$ was performed and was plated (100 $\mu \mathrm{L} /$ well) onto $96-w e l l$ plates. Diluted ranges of sample extracts were added to each well with identified concentrations of $100,50,25,10$, and $1 \mu \mathrm{g} / \mathrm{mL}$ further incubated for 72 hours. MTT solution was added at the end of incubation to the cells and incubation was then further continued for 3 hours. After solubilization of the purple formazan crystals using DMSO, the optical density of the samples was measured using an ELISA reader at a wavelength of $570 \mathrm{~nm}$.

Cytotoxicity was recorded as the concentration causing $50 \%$ growth inhibition of the cells $\left(\mathrm{IC}_{50}\right.$ value) using the formula given below:

Cell viability $(\%)=\frac{\text { Absorbance sample }(\text { mean })}{\text { Absorbance control }(\text { mean })} \times 100 \%$

\section{Results and discussion Solubility of KMO in oil}

Vegetable oils contain many beneficial fatty acids that are widely used in cosmeceutical formulation. The therapeutic effects are well maintained when they are encapsulated in nano carrier systems. ${ }^{13}$ The solubility of KMO in a mixture of selected oil:LO at a ratio of 9:1 was studied. Based on the centrifugation force test, all mixtures showed separation of layers and demonstrated precipitation at the bottom of the test tube except for VCO and CO mixtures. Both oils, VCO and CO, showed good homogeneity toward LO and the active ingredient, KMO. However, $\mathrm{CO}$ was chosen over VCO because it contained a higher percentage of ricinoleic acid (89\%) as compared to the other carrier oil, which usually is used in the pharmaceuticals and cosmetics industries. ${ }^{14} \mathrm{CO}$ enriched with anti-inflammatory properties provides a moisturizing effect and stimulates collagen. ${ }^{15}$ Moreover, $\mathrm{CO}$ was chosen because it is more cosmeceutical desirable as oil based on having a lower comedogenicity rating than $\mathrm{VCO}$. The comedogenicity rating defines how various oils and emollients are categorized based on the degree to which they are likely to clog pores which may lead to breakouts, and irritant and allergic reactions to human skin. ${ }^{16}$

\section{Fitting the model}

The compositional aspect of the response (droplet size) of nanoemulsion obtained experimentally based on the D-optimal MED model is tabulated in Table 2. The table shows that the minimum droplet size obtained was $155.87 \mathrm{~nm}$ (run no. 13). The actual droplet size values were mostly in good agreement with the predicted values. The final equation

Table 2 Experimental data and actual and predicted values of droplet size of the nanoemulsion obtained from the D-optimal mixture experimental design model

\begin{tabular}{llllllll}
\hline Run & A & B & C & D & E & \multicolumn{2}{c}{ Droplet size (nm) } \\
\cline { 5 - 8 } & & & & & & Actual & Predicted \\
\hline 1 & 2.50 & 1.00 & 2.00 & 0.50 & 93.30 & 161.97 & 162.26 \\
3 & 2.50 & 3.00 & 6.00 & 1.00 & 86.80 & 164.47 & 172.50 \\
4 & 4.00 & 5.00 & 2.00 & 1.50 & 86.80 & 276.87 & 268.22 \\
5 & 4.00 & 5.00 & 6.00 & 1.50 & 82.80 & 169.67 & 136.55 \\
6 & 2.50 & 3.00 & 6.00 & 1.00 & 86.80 & 163.43 & 172.50 \\
7 & 4.00 & 5.00 & 10.00 & 0.50 & 79.80 & 167.80 & 176.91 \\
8 & 1.00 & 3.00 & 2.00 & 1.50 & 91.80 & 435.13 & 386.59 \\
9 & 4.00 & 3.00 & 2.00 & 0.50 & 89.80 & 265.83 & 305.63 \\
10 & 2.50 & 3.00 & 6.00 & 1.00 & 86.80 & 160.33 & 172.50 \\
11 & 1.00 & 5.00 & 6.00 & 1.50 & 85.80 & 214.60 & 287.10 \\
13 & 4.00 & 3.00 & 10.00 & 1.50 & 80.80 & 155.87 & 181.53 \\
14 & 1.00 & 1.00 & 2.00 & 1.00 & 94.30 & 335.60 & 335.89 \\
16 & 1.00 & 5.00 & 10.00 & 1.50 & 81.80 & 187.67 & 154.43 \\
18 & 1.00 & 1.00 & 10.00 & 1.50 & 85.80 & 551.00 & 475.91 \\
19 & 4.00 & 1.00 & 10.00 & 0.50 & 83.80 & 344.63 & 413.85 \\
20 & 1.00 & 3.00 & 10.00 & 0.50 & 84.80 & 261.30 & 244.67 \\
21 & 1.00 & 1.00 & 6.00 & 0.50 & 90.80 & 276.90 & 313.94 \\
22 & 2.50 & 3.00 & 6.00 & 1.00 & 86.80 & 161.17 & 172.50 \\
24 & 4.00 & 1.00 & 6.00 & 0.50 & 87.80 & 389.87 & 313.75 \\
\hline$N$
\end{tabular}

Notes: The letters A-E represent the independent variables, where $A$ is Tween 80 , $B$ is CO:LO, C is KMO, D is xanthan gum, and $E$ is deionized water.

Abbreviations: CO, castor oil; LO, lemon essential oil; KMO, kojic monooleate. 
Table 3 ANOVA results for the effect of the five variables

\begin{tabular}{|c|c|c|c|c|c|c|}
\hline Source & Sum of squares & $d f$ & Mean square & F-value & $P$-value & Significant \\
\hline Model & $2.278 \times 10^{5}$ & 14 & $16,267.88$ & $2,479.87$ & $<0.0001$ & Significant \\
\hline Linear mixture & $87,158.88$ & 4 & $21,789.72$ & $3,321.62$ & $<0.0001$ & \\
\hline$A B$ & $1,344.13$ & I & I,344.I3 & 204.90 & 0.0001 & \\
\hline$A C$ & $16,215.57$ & I & $16,215.57$ & $2,47 I .90$ & $<0.0001$ & \\
\hline$A D$ & $7,528.55$ & I & $7,528.55$ & $\mathrm{I}, 147.65$ & $<0.0001$ & \\
\hline $\mathrm{AE}$ & II,I35.03 & 1 & $\mathrm{II}, 135.03$ & $\mathrm{I}, 697.42$ & $<0.0001$ & \\
\hline $\mathrm{BC}$ & 698.26 & I & 698.26 & 106.44 & 0.0005 & \\
\hline BD & $2,384.49$ & 1 & $2,384.49$ & 363.49 & $<0.0001$ & \\
\hline $\mathrm{BE}$ & 271.62 & 1 & 271.62 & 41.41 & 0.0030 & \\
\hline CD & $3,634.24$ & 1 & $3,634.24$ & 554.00 & $<0.0001$ & \\
\hline CE & I,698.06 & I & I,698.06 & 258.85 & $<0.0001$ & \\
\hline DE & $2,648.28$ & $\mathrm{I}$ & $2,648.28$ & 403.70 & $<0.0001$ & \\
\hline Residual & 26.24 & 4 & 6.56 & & & \\
\hline Lack of fit & 15.11 & 1 & 15.11 & 4.07 & 0.1370 & Not significant \\
\hline Pure error & 11.13 & 3 & 3.71 & & & \\
\hline Cor total & $2.278 \times 10^{5}$ & 18 & & & & \\
\hline
\end{tabular}

Notes: The letters A-E represent the independent variables, where A is Tween $80, \mathrm{~B}$ is CO:LO, C is KMO, D is xanthan gum, and $\mathrm{E}$ is deionized water. Abbreviations: CO, castor oil; cor total, corrected total sum of squares; $\mathrm{LO}$, lemon essential oil; KMO, kojic monooleate.

to predict the droplet size in terms of actual factors of the composition mixture can be calculated as follows:

$$
\begin{aligned}
\mathrm{Y}= & 4,056.90552 \mathrm{~A}-580.81618 \mathrm{~B}-92.24499 \mathrm{C}+ \\
& 20,716.74879 \mathrm{D}-0.30839 \mathrm{E}-28.66504 \mathrm{AB}- \\
& 51.52846 \mathrm{AC}-330.68371 \mathrm{AD}-41.51825 \mathrm{AE}+ \\
& 10.04221 \mathrm{BC}-224.21925 \mathrm{BD}+5.22279 \mathrm{BE}- \\
& 246.21684 \mathrm{CD}+1.74513 \mathrm{CE}-205.63860 \mathrm{DE}
\end{aligned}
$$

where A, B, C, D, and E represent the fractions of Tween80, $\mathrm{CO}: \mathrm{LO}, \mathrm{KMO}$, xanthan gum, and deionized water in $\mathrm{w} / \mathrm{w}$ $\%$, respectively.

ANOVA results for the effect of five variables were implemented using Design Expert software (version 7.1.5) to investigate the suitability and significance of the final model (Table 3 ). The quadratic model was significant with $F$-value $(2,479.87)$ and $P$-value $(<0.0001)$, and the lack of fit was not significant toward the response (droplet size). All linear mixture components (A, B, C, D, and E) from Equation 6 were adequate in the response based on their coefficients and the $P$-value of the linear mixture. The regression coefficient results for the final reduced model (Table 4) showed that the predicted $R^{2}(0.9109)$ was in true agreement with the adjusted $R^{2}(0.9995)$. According to the results obtained, $>90 \%$ of the response variations in the independent variables (droplet size) can be explained by the D-optimal MED as a function of the main composition.

\section{D-optimal analysis}

Cosmeceutical products with nanosizes ranging between 20 and $200 \mathrm{~nm}$ are more desirable as the size would be easier to carry active ingredients to penetrate through the stratum corneum of the skin. Therefore, by using nanosized molecules, the potential active ingredient may pass through the pores and hair follicles of the skin and mucosal membranes, without disrupting normal tissues. ${ }^{17,18}$ Therefore, the minimum droplet size is the main consideration for this design. Figures 1 and 2 show the optimization of KMO-enriched $\mathrm{O} / \mathrm{W}$ nanoemulsions contours and three-dimensional surface graphs on droplet size using the Design Expert software (version 7.1.5). Based on Figure 1, increasing the surfactant concentration (Tween80) will eventually decrease the droplet size. This is because Tween 80 acts as an emulsifier to lower

Table 4 Regression coefficient results for the final reduced model

\begin{tabular}{llll}
\hline Source & $\begin{array}{l}\text { Coefficient } \\
\text { estimate }\end{array}$ & $\begin{array}{l}\text { Regression } \\
\text { coefficient }\end{array}$ & $\begin{array}{l}\text { Droplet } \\
\text { size }\end{array}$ \\
\hline A, Tween 80 & $10,114.41$ & SD & 2.56 \\
B, CO:LO & $-2,336.06$ & PRESS & $20,300.58$ \\
C, KMO & 393.98 & $R^{2}$ & 0.9109 \\
D, xanthan gum & $57,744.61$ & Adjusted $R^{2}$ & 0.9995 \\
E, deionized water & 128.23 & Predicted $R^{2}$ & 0.9109 \\
AB & $-7,338.25$ & Adequate precision & 173.108 \\
AC & $-13,191.29$ & & \\
AD & $-84,655.03$ & & \\
AE & $-10,628.67$ & & \\
BC & $2,570.81$ & & \\
BD & $-57,400.13$ & & \\
BE & $1,337.03$ & & \\
CD & $-63,031.51$ & & \\
CE & 446.75 & & \\
DE & $-52,643.48$ & & \\
\hline N & & & \\
\hline
\end{tabular}

Notes: The letters A-E represent the independent variables, where $A$ is Tween 80 , $B$ is CO:LO, C is KMO, D is xanthan gum, and $E$ is deionized water.

Abbreviations: CO, castor oil; LO, lemon essential oil; KMO, kojic monooleate; PRESS, predicted residual error sum of squares. 


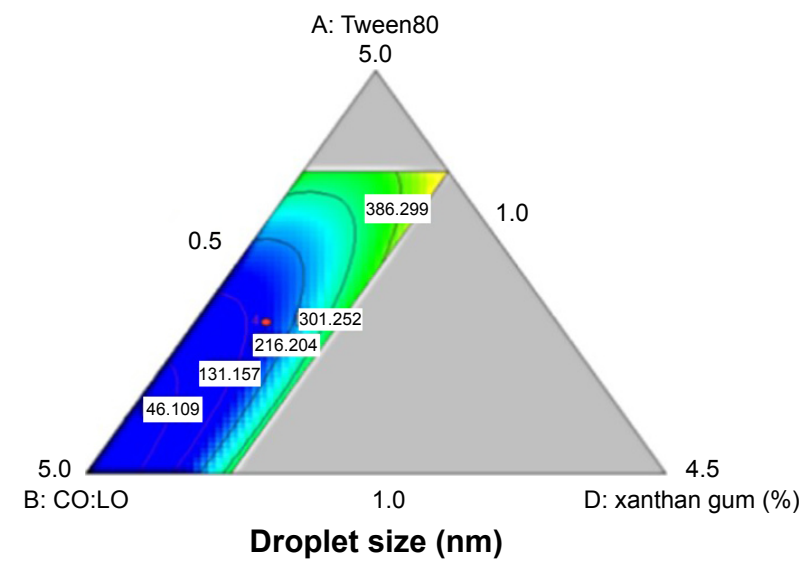

Droplet size $(\mathrm{nm})$

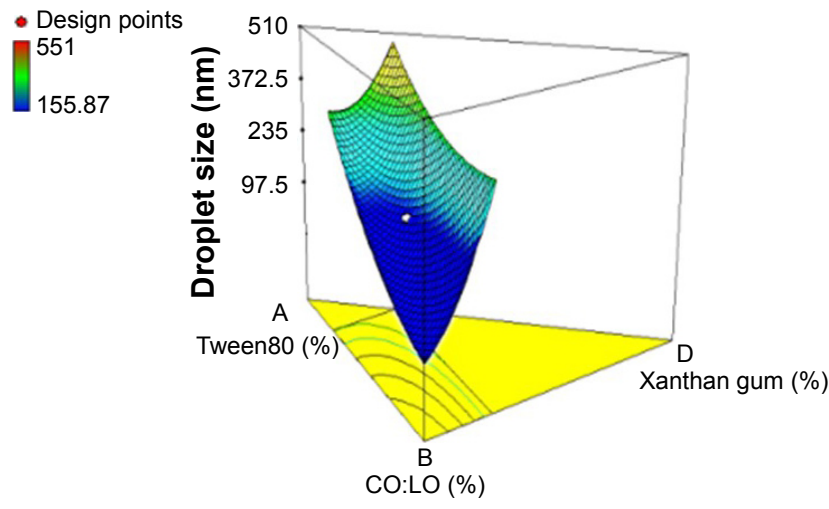

Figure I Contour plot of three-dimensional surface and two-dimensional plot showing the interaction effect between variables A (Tween80), B (CO:LO), and $\mathrm{D}$ (xanthan gum) on droplet size $(\mathrm{nm})$ of the nanoemulsion; $\mathrm{C}(\mathrm{KMO})$ and $\mathrm{E}$ (water) are kept constant.

Abbreviations: $\mathrm{CO}$, castor oil; LO, lemon essential oil; KMO, kojic monooleate.

the interfacial tension whereby the Laplace pressure, $P$, and the stress needed for droplet deformation are reduced. ${ }^{19}$ This behavior was similar for the concentration of oils (CO:LO) in the KMO-enriched nanoemulsion. When the concentration of oils increased, the droplet size also decreased. Tween 80 and the oils mixture (CO:LO) were the vital compositions that ensured decreasing effects of droplets size of KMO-enriched $\mathrm{O} / \mathrm{W}$ nanoemulsion.

From Figure 2, it is obvious that increasing the xanthan gum concentration will decrease droplet sizes. Xanthan gum was used as a thickening agent in the nanoemulsion system. It would provide a gel network in the continuous phase and would form a network that keeps the water molecules from easily sliding from each other. Thus, this would provide a thicker structure and viscosity to the nanoemulsion. ${ }^{20}$ The more the xanthan gum concentration along with higher amount of deionized water, the more viscous the aqueous phase. Despite that, a low amount of deionized water with a higher concentration of xanthan gum would give rise to a

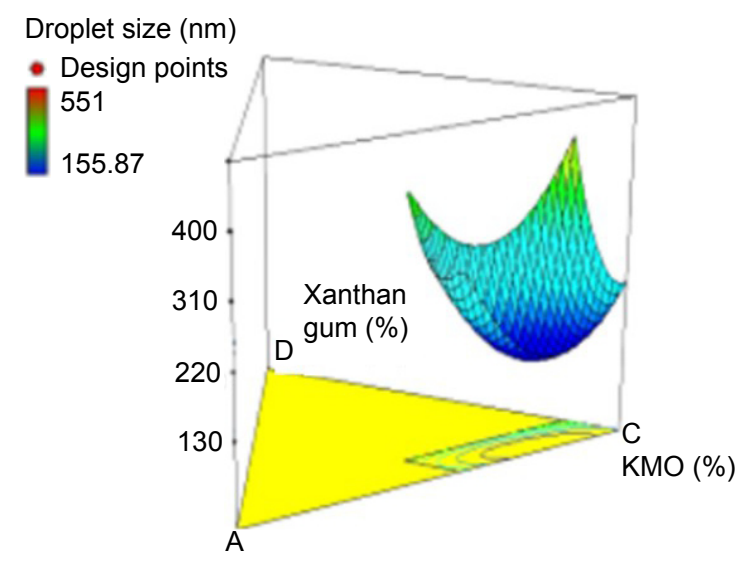

Tween80 (\%)

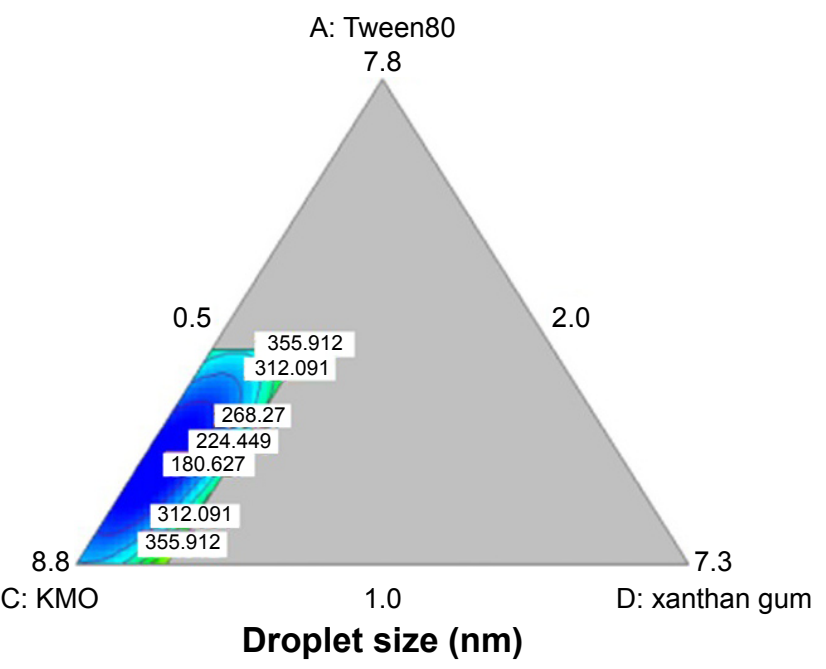

Figure 2 Contour plot of three-dimensional surface and two-dimensional plot showing the interaction effect between variables $A$ (Tween80), C (KMO), and D (xanthan gum) on droplet size (nm) of the nanoemulsion; B (CO:LO) and E (water) are kept constant.

Abbreviations: CO, castor oil; LO, lemon essential oil; KMO, kojic monooleate; T80, Tween 80.

more viscous nanoemulsion making it difficult to homogenize with other compositions. Larger droplet sizes occur when the viscosity in the system increases due to the efficiency of decreased particle disruption. The same observation has been described earlier by Krstonošić et al and Rodd et al in the use of xanthan gum as an emulsifier. ${ }^{21,22}$ Decreasing the active ingredient content and increasing the surfactant concentrations seem to ensure smaller droplet sizes of the nanoemulsion. However, at a certain point, decreasing and increasing the active ingredient and surfactant, respectively, show an increase in droplet size. The surfactant and oil mixture reaches the overlap concentration where the molecules begin to physically interact each other. Thus, after that overlap concentration, flocculation occurs and promotes larger droplet size. ${ }^{22}$ 
Table 5 Validation set for seven different formulations of $\mathrm{KMO}$-enriched $\mathrm{O} / \mathrm{W}$ nanoemulsion

\begin{tabular}{|c|c|c|c|c|c|c|c|}
\hline \multicolumn{5}{|l|}{ Variables } & \multicolumn{2}{|c|}{ Droplet size (nm) } & \multirow[t]{2}{*}{ RSE (\%) } \\
\hline $\begin{array}{l}\text { Tween } 80 \\
\text { (\%) }\end{array}$ & $\begin{array}{l}\text { CO:LO } \\
\text { (\%) }\end{array}$ & $\begin{array}{l}\text { KMO } \\
(\%)\end{array}$ & $\begin{array}{l}\text { Xanthan } \\
\text { gum (\%) }\end{array}$ & $\begin{array}{l}\text { Deionized } \\
\text { water (\%) }\end{array}$ & Actual & Predicted & \\
\hline 3.50 & 2.80 & 2.00 & 1.50 & 89.50 & 182.70 & 179.69 & 1.67 \\
\hline 4.00 & 4.00 & 3.80 & 1.50 & 86.00 & 190.80 & 192.26 & 0.75 \\
\hline 3.00 & 3.50 & 3.00 & 1.50 & 88.30 & 169.00 & 169.40 & 0.23 \\
\hline 3.80 & 5.00 & 8.50 & 0.50 & 81.50 & 186.50 & 185.74 & 0.40 \\
\hline 4.00 & 3.50 & 10.00 & 1.20 & 80.60 & 181.30 & 180.46 & 0.46 \\
\hline 3.78 & 4.20 & 8.50 & 0.80 & 82.02 & 131.48 & 130.37 & 0.85 \\
\hline 3.80 & 4.30 & 8.27 & $\mathrm{I} .45$ & 81.48 & 120.20 & 122.22 & 1.65 \\
\hline
\end{tabular}

Abbreviations: $\mathrm{CO}$, castor oil; LO, lemon essential oil; KMO, kojic monooleate; RSE, residual standard error; O/W, oil-in-water.

\section{Verification of model}

The actual and predicted response values of certain randomized formulations are evaluated in Table 5 to test the sufficiency of the final obtained model. Seven different formulations were selected. No significant difference was found between the actual and predicted response values which gave a desirable indication of the fitness model developed.

Results were studied of the predicted values by calculating the RSE as shown in Equation 7:

$$
\text { RSE } \%=\frac{\text { Actual value }- \text { Predicted value }}{\text { Predicted value }} \times 100 \%
$$

Based on the validation set, \% RSE was $<2.00$ which indicated no significant difference between the actual and predicted values. This demonstrated that a good model was obtained.

\section{Optimization of the responses}

The optimized formulation was developed based on the maximum amount of $\mathrm{KMO}$ resulting in the minimum droplet size of the nanoemulsion (Table 6). Based on the D-optimal MED, an optimized formulation with the composition of KMO $(10.00 \% \mathrm{w} / \mathrm{w})$, Tween $80(3.19 \% \mathrm{w} / \mathrm{w})$, CO:LO $(3.74 \% \mathrm{w} / \mathrm{w})$, xanthan gum $(0.70 \% \mathrm{w} / \mathrm{w})$, and deionized

Table 6 Constraints of numerical optimization

\begin{tabular}{llll}
\hline Constraints & Goal & $\begin{array}{l}\text { Lower } \\
\text { limit }\end{array}$ & $\begin{array}{l}\text { Upper } \\
\text { limit }\end{array}$ \\
\hline Tween 80 & In range & 1.00 & 4.00 \\
CO:LO & In range & 1.00 & 5.00 \\
KMO & Maximize & 2.00 & 10.00 \\
Xanthan gum & In range & 0.50 & 1.50 \\
Deionized water & In range & 78.80 & 94.80 \\
Droplet size & Minimize & 155.87 & 551.00 \\
\hline
\end{tabular}

Abbreviations: $\mathrm{CO}$, castor oil; LO, lemon essential oil; KMO, kojic monooleate. water $(81.68 \% \mathrm{w} / \mathrm{w})$ was suggested wherein the nanoemulsion would have a droplet size of $110.01 \pm 0.14 \mathrm{~nm}$. Table 7 shows the response values of the optimized KMO formulation. The desirability of the optimum KMO formulation was 1.00 . This showed that the quality of the formulation was agreeable and excellent. However, it was reported that when the value was 0.63 , the formulation quality would be considered insufficient. ${ }^{23}$

\section{Physicochemical characterization of optimized KMO nanoemulsion}

Mean droplet size, zeta potential, and PDI analysis

Based on the optimized formulation, a droplet size of $110.01 \pm 0.14 \mathrm{~nm}$ with PDI $0.25 \pm 0.01$ was obtained, indicating a monodisperse system. The zeta potential value of $-43.60 \pm 0.23 \mathrm{mV}$ demonstrated higher electrostatic repulsion which ensured that the nanoemulsion system was stable. The zeta potential measures the electrokinetic potential of a particle and determines the stability of the formulation system. The formulation is considered stable when the value is more than $+25 \mathrm{mV}$ and lower than $-25 \mathrm{mV} .{ }^{24} \mathrm{PDI}$ analyzes the size distribution and the abundant amount of light scattered can be determined from various sizes of the nanoemulsion. The PDI value of the optimized formulation indicated a fairly monodisperse system (PDI $<0.25$ ). ${ }^{25,26}$ Nanoemulsions with a droplet size ranging between 100 and $200 \mathrm{~nm}$ are more favorable for cosmeceutical purpose as suggested by Ngan et al. ${ }^{27}$

\section{Morphology}

Figure 3 presents the TEM image of the KMO-enriched O/W nanoemulsion. The spherical shape of the oil droplets was distributed uniformly and homogenously throughout the formulation without any aggregation in the system. Moreover, the droplet size analyzed from TEM corresponded with the size obtained from the Zetasizer analysis. 
Table 7 Optimum formulation of KMO-enriched O/W nanoemulsion

\begin{tabular}{|c|c|c|c|c|c|c|c|}
\hline \multicolumn{5}{|l|}{ Variables } & \multicolumn{2}{|c|}{ Droplet size $(\mathrm{nm})$} & \multirow[t]{2}{*}{ Desirability } \\
\hline $\begin{array}{l}\text { Tween } 80 \\
\text { (\%) }\end{array}$ & $\begin{array}{l}\text { CO:LO } \\
(\%)\end{array}$ & $\begin{array}{l}\text { KMO } \\
(\%)\end{array}$ & $\begin{array}{l}\text { Xanthan } \\
\text { gum (\%) }\end{array}$ & $\begin{array}{l}\text { Deionized } \\
\text { water }(\%)\end{array}$ & Actual & Predicted & \\
\hline 3.19 & 3.74 & 10.0 & 0.70 & 81.68 & $110.01 \pm 0.14$ & 111.73 & 1.00 \\
\hline
\end{tabular}

Abbreviations: CO, castor oil; LO, lemon essential oil; KMO, kojic monooleate; O/W, oil-in-water.

\section{$\mathrm{pH}$ and conductivity measurement}

The $\mathrm{pH}$ value of the optimized formulation was $6.28 \pm 0.01$ showing its suitability to be used topically as stated by Martínez et al, who reported that the $\mathrm{pH}$ values should be in the range of 4.0-7.0. ${ }^{28}$ The KMO nanoemulsion was detected to be $\mathrm{O} / \mathrm{W}$ nanoemulsions since high conductivity measurements $\left(14,92.00 \pm 0.03 \mu \mathrm{Scm}^{-1}\right)$ were obtained. Conductivity refers to the measurement of the free amount of water and ions in a system; this could therefore investigate the ability of the nanoemulsion to conduct electricity, which in turn would determine if the system formed is an $\mathrm{O} / \mathrm{W}$ or $\mathrm{W} / \mathrm{O}$ system. Studies by Korhonen et al have reported that $\mathrm{O} / \mathrm{W}$ systems possess higher conductivity measurements than $\mathrm{W} / \mathrm{O}$ systems because the external phase is water. In addition, an $\mathrm{O} / \mathrm{W}$ nanoemulsion was more favorable in the formulation of cosmeceutical products because it is less greasy and more economical. ${ }^{29}$

\section{Rheological study}

The behavior of the respective nanoemulsions can be determined by utilizing two rheological tests: 1) steady state and 2) oscillatory state. The KMO-enriched $\mathrm{O} / \mathrm{W}$ nanoemulsion demonstrated a shear thinning behavior in both tests. The existence of weak attractive forces (weak elastic gel-like network) between the nanoemulsion droplets showed that the system had a shear thinning behavior. ${ }^{30}$ Shear thinning (pseudo-plastic) formulation exhibits a low viscosity fluid behavior (low resistance) to flow when tested under high shear conditions and zero flow under gravity stress. The cosmetic and pharmaceutical industries usually
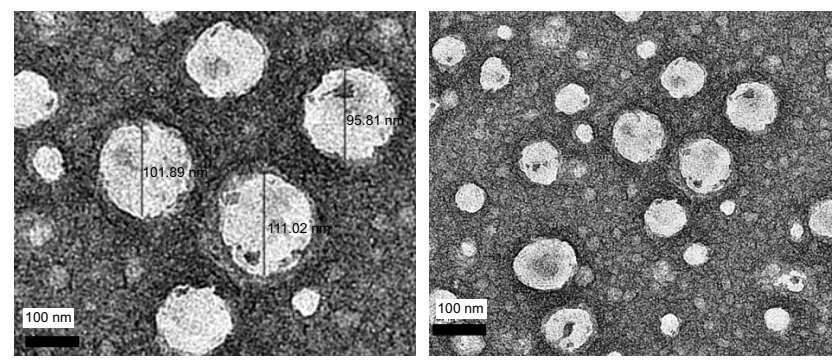

Figure 3 TEM images of KMO-enriched O/W nanoemulsion.

Abbreviations: TEM, transmission electron microscopy; KMO, kojic monooleate; $\mathrm{O} / \mathrm{W}$, oil-in-water. demand more of this type of behavior for topical formulation products..$^{31}$ Flow behavior index $(n)$ can be used to determine the rheological properties of the nanoemulsion. These showed the properties of the $n$ value of fluid based on Equation 2. KMO with $n<1$ showed the fluid had shear thinning properties. Figure 4 demonstrates that the optimized $\mathrm{KMO}$-enriched $\mathrm{O} / \mathrm{W}$ nanoemulsion had a shear thinning behavior. Viscosity of the optimized formulation decreased with the increase of shear rate indicating that the formulation exhibits non-Newtonian pseudo-plastic $(n<1)$ fluid. Table 8 shows the non-Newtonian pseudo-plastic behavior properties of the optimized KMO-enriched $\mathrm{O} / \mathrm{W}$ nanoemulsion using the power law model in Equation 2.

Figure 5 shows that the optimized $\mathrm{KMO}$-enriched $\mathrm{O} / \mathrm{W}$ nanoemulsion exhibits pseudo-plastic behavior (nonlinear relationship) in the steady state test. Besides, the higher value of consistency coefficients, $k$ (7.1033), of the optimized formulations indicated that a stronger nanoemulsion structure was prepared. A desirable nanoemulsion with elastic properties is more preferable for cosmeceutical application. In the oscillatory test, the KMO-enriched $\mathrm{O} / \mathrm{W}$ nanoemulsion exhibited elastic properties as shown in Figure 6. Based on the LVR, the optimized nanoemulsion showed a higher $\mathrm{G}^{\prime}$ value (storage modulus) with elastic component compared to $\mathrm{G}^{\prime \prime}$ value (loss modulus) with viscous component. ${ }^{30}$ This proved that the KMO nanoemulsion exhibited an elastic behavior system. $G^{\prime}$ and $G^{\prime \prime}$ were steady at low deformation with undamaged and better structured nanoemulsion. Hence, the broad LVR allowed the optimized KMO-enriched O/W nanoemulsion to acquired good rigidity and stability toward phase separation.

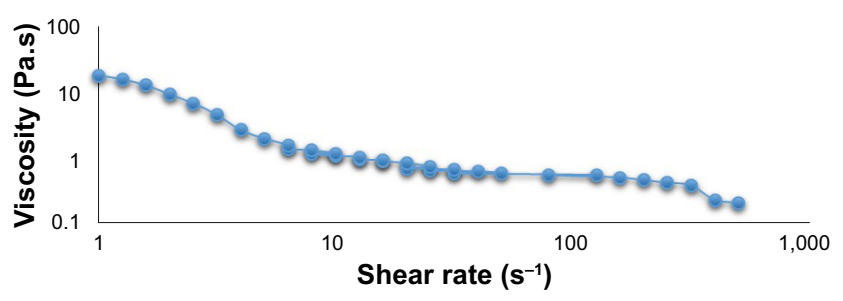

Figure 4 Graph of viscosity (Pa.s) vs shear rate $\left(\mathrm{s}^{-1}\right)$ of the optimized KMO-enriched nanoemulsion.

Abbreviation: $\mathrm{KMO}$, kojic monooleate. 
Table 8 Flow behavior indices ( $n)$, consistency coefficients $(k)$, and regression coefficients $\left(R^{2}\right)$ of the KMO-enriched O/W nanoemulsion

\begin{tabular}{llll}
\hline Formulation & $\boldsymbol{k}$ & $\boldsymbol{n}$ & $\boldsymbol{R}^{2}$ \\
\hline KMO-enriched O/W nanoemulsion & 7.1033 & 0.3830 & 0.8253 \\
\hline
\end{tabular}

Abbreviations: KMO, kojic monooleate; O/W, oil-in-water.

\section{Accelerated stability study}

Determination of the optimized formulation on the creaming or sedimentation (phase separation) rate can be examined by the centrifugation test. Hadzir et al suggested that the formulation's shelf life can be estimated by this test..$^{32}$ The optimized formulation tested displayed no phase separation after centrifugation at 4,000 rpm for 15 minutes. The properties of the formulation would be affected if phase separation occurred. Thus, this indicates good stability of the formulation. The physical stability of the KMO-enriched $\mathrm{O} / \mathrm{W}$ nanoemulsion at different storage temperatures $\left(25^{\circ} \mathrm{C}, 45^{\circ} \mathrm{C}\right.$, and $4^{\circ} \mathrm{C}$ ) for a period of 90 days is shown in Table 9.

Stability studies were carried out for coalescence rate, Ostwald ripening, and freeze-thaw cycles for better understanding. Based on Figure 7, the KMO nanoemulsion at three different temperatures showed an increment in droplet size. However, the nanoemulsion at $25^{\circ} \mathrm{C}$ and $4{ }^{\circ} \mathrm{C}$ was only able to maintain its nanosize $(20-200 \mathrm{~nm})$ range. In addition, the nanoemulsion was able to maintain homogeneity at three different temperatures up to 90 days even at a higher temperature $\left(45^{\circ} \mathrm{C}\right)$. The capability of the nanoemulsion to withstand the temperatures might be due to the nonionic surfactant, Tween 80 , wherein it forms a steric barrier at the oil or water interface and prevents droplet collision. ${ }^{30}$ Stoke's law states that the rate of creaming or sedimentation is inversely proportional to the continuous viscosity phase. The viscosity of the formulation increases with the addition of xanthan gum in the system. Xanthan gum would reduce the droplets collision and therefore reduce the coalescence effect. ${ }^{32}$

Under coalescence, two or more droplets fuse together to form bigger droplets in the system. Figure 8 shows the plotted graph of $1 / r^{2}$ vs storage time. The graph suggests a linear relationship pattern for coalescence effect to occur. Based on the graph, all the droplet size values did not produce a linear pattern. Thus, the increase in droplet size over time was not created by coalescence. ${ }^{20}$

Ostwald ripening occurs when particles of the discontinuous phase diffuse from small to larger droplet sizes through the continuous phase (water) of the nanoemulsion system. ${ }^{33}$ The stability of the nanoemulsion can be investigated by plotting $r^{3}$ vs storage time for determining the rate of Ostwald ripening. The $\mathrm{KMO}$-enriched $\mathrm{O} / \mathrm{W}$ nanoemulsion under three different temperatures during 90 days of storage was affected by Ostwald ripening (Figure 9). The droplet size of the nanoemulsion increased slowly during storage at $25^{\circ} \mathrm{C}$ resulting in low Ostwald ripening effect. In contrast, storage temperatures of $4^{\circ} \mathrm{C}$ and $45^{\circ} \mathrm{C}$ resulted in higher Ostwald ripening effect; thus, the droplet size became larger showing low stability of the nanoemulsion as compared to storage at the room temperature $\left(25^{\circ} \mathrm{C}\right)$.

The KMO-enriched $\mathrm{O} / \mathrm{W}$ nanoemulsion remained in the homogenous phase (stable) even after undergoing five cycles over 10 days under the freeze-thaw cycling test. However, the droplet size of the emulsion slightly increased from 110.01 to $120.67 \mathrm{~nm}$, which still lies in the nanosize range. The actual color of the KMO nanoemulsion changed from white to a yellowish emulsion which may due to the emulsifier which exhibits higher interfacial tension and caused Laplace

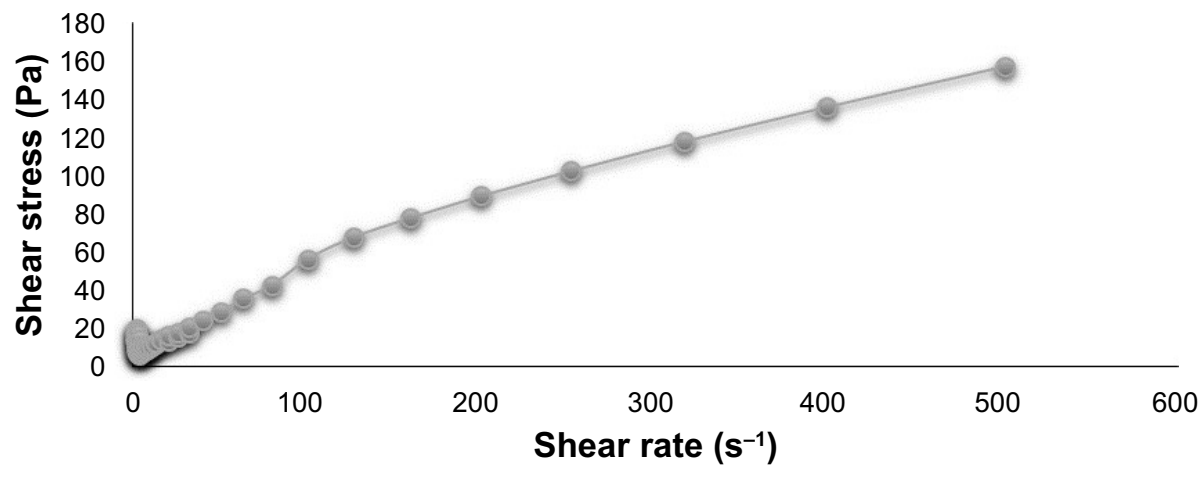

Figure 5 Graph of steady state test: shear stress $(\mathrm{Pa})$ vs shear rate $\left(\mathrm{s}^{-1}\right)$ of $\mathrm{KMO}$-enriched O/W nanoemulsion. Abbreviations: KMO, kojic monooleate; O/W, oil-in-water. 


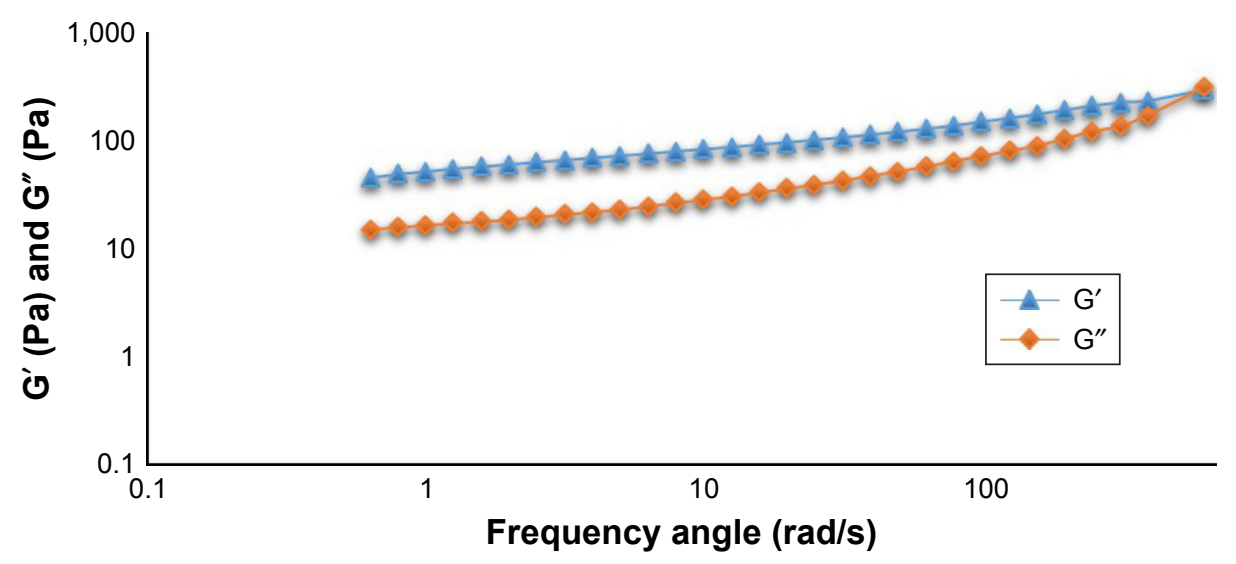

Figure 6 Graph of oscillatory state test: G' (storage modulus) and G" (loss modulus) against frequency angle of KMO-enriched O/W nanoemulsion. Abbreviations: $\mathrm{KMO}$, kojic monooleate; O/W, oil-in-water; rad, radian.

pressure, $P$, and the stress to form larger droplet sizes and changes in color. Besides, the emulsifier at the interfacial layer formed a physical (steric) barrier between prooxidants and the lipid phase. Thus, in this case, the changes of size and color of the nanoemulsion impacted lipid oxidation remarkably. ${ }^{34,35}$

At higher temperatures, the kinetic energy and collision rate increased between the oil droplets causing coalescence of nanoemulsion droplets. Freezing the nanoemulsion would cause the aqueous phase to solidify easily. Alternate conditions of freezing and thawing interrupt the nanoemulsion system leading to an increment of droplet size. ${ }^{36}$ However, the addition of hydrocolloids (xanthan gum) in the nanoemulsion system helped the system to retain smaller droplet sizes and stability.

\section{Thermal analysis}

TGA is one of the techniques used to distinguish thermal stability and physicochemical characteristics of $\mathrm{KMO}$-enriched $\mathrm{O} / \mathrm{W}$ nanoemulsions by percent weight loss. The TGA thermogram (Figure 10) indicates three distinct transformation regions with a mass loss observed in the

Table 9 Stability of the KMO-enriched O/W nanoemulsion at different storage temperatures

\begin{tabular}{|c|c|c|c|}
\hline \multirow{2}{*}{$\begin{array}{l}\text { Storage } \\
\text { temperature } \\
\left({ }^{\circ} \mathrm{C}\right)\end{array}$} & $\begin{array}{l}\text { Stability storage } \\
\text { (days) }\end{array}$ & \multirow[t]{2}{*}{ Centrifugation } & \multirow[t]{2}{*}{$\begin{array}{l}\text { Freeze-thaw } \\
\text { (5 cycles) }\end{array}$} \\
\hline & $\overline{171421306090}$ & & \\
\hline 4 & $\begin{array}{llllll}\sqrt{ } & \sqrt{ } & \sqrt{ } & \sqrt{ } & \sqrt{ } & \sqrt{ }\end{array}$ & $\sqrt{ }$ & $\sqrt{ }$ \\
\hline 25 & $\begin{array}{lllllll}\sqrt{ } & \sqrt{ } & \sqrt{ } & \sqrt{ } & \sqrt{ } & \sqrt{ }\end{array}$ & & \\
\hline 45 & $\begin{array}{llllll}\sqrt{ } & \sqrt{ } & \sqrt{ } & \sqrt{ } & \sqrt{ } & \sqrt{ }\end{array}$ & & \\
\hline
\end{tabular}

Note: Stable: $\sqrt{ }$.

Abbreviations: $\mathrm{KMO}$, kojic monooleate; O/W, oil-in-water. system. The melting of KMO nanoemulsion first occurred at $53.34^{\circ} \mathrm{C}$ with a weight loss of $67.45 \%$ which may be due to the removal of the continuous phase (deionized water) in the nanoemulsion. The second stage of weight loss was observed in the temperature range of $190.01^{\circ} \mathrm{C}-336.54^{\circ} \mathrm{C}$. At very high temperatures, $6.26 \%$ of the residue was left and was completely decomposed at $494.97^{\circ} \mathrm{C}$. This could be because of the decomposition process of oil occurring during the combustion of organic-bound carbon in the oil. Shorter time with broader temperature ranges was needed to decompose the nanoemulsion over higher temperatures. ${ }^{24}$

\section{Cytotoxicity assay of the optimized KMO-enriched O/W nanoemulsion}

The toxicity test was implemented to test the safety assessment of the final formulations. Toxicity between the optimized KMO formulation and KMO oil was tested on the mouse embryonic fibroblast cell line (3T3). Concentrationdependent cytotoxicity of the samples was examined by MTT colorimetric assay to determine the cellular response of the $3 \mathrm{~T} 3$ cells. Figure 11 shows $\mathrm{IC}_{50}$ value $(50 \%$ inhibition of cell viability) between the KMO formulation and KMO oil. The MTT assay indicated that the cell viability decreased by increasing concentrations of samples to $>50 \%$ at the highest concentration of $100 \mu \mathrm{g} / \mathrm{mL}$. The $\mathrm{IC}_{50}$ value of both the $\mathrm{KMO}$ formulation and $\mathrm{KMO}$ oil was $>100 \mu \mathrm{g} / \mathrm{mL}$. Moreover, cell survival on KMO formulation was found to be higher compared to KMO oil. This suggested that the KMO formulation was safe and could be used for cosmeceutical applications since the $\mathrm{IC}_{50}$ value of the formulation did not reach the highest concentration tested as an $\mathrm{IC}_{50}$ value $>30 \mu \mathrm{g} / \mathrm{mL}$ was considered less toxic. ${ }^{37}$ 


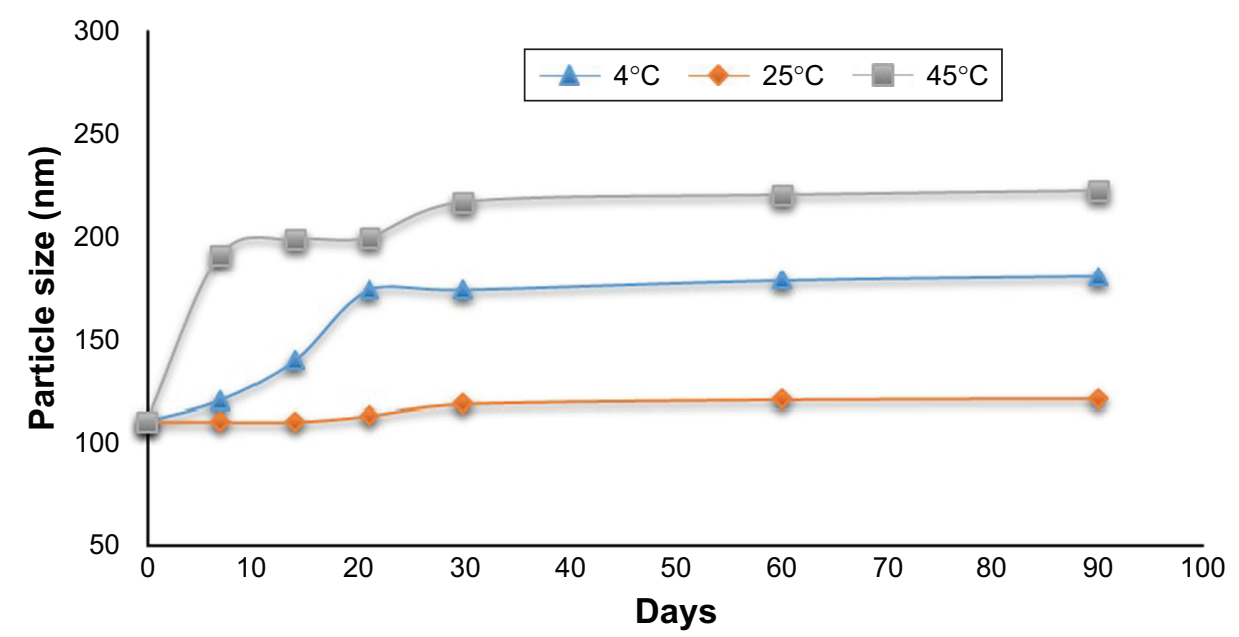

Figure 7 Graph of droplet size (nm) observed for 90 days at three different temperatures.

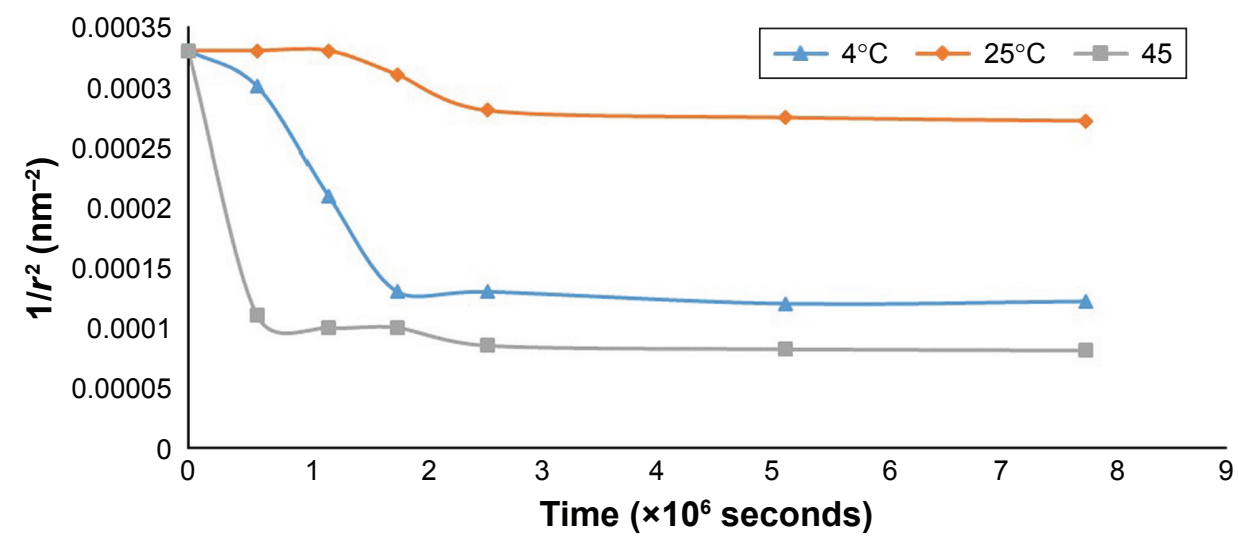

Figure 8 Graph of $\mathrm{I} / \mathrm{r}^{2}$ vs storage time.

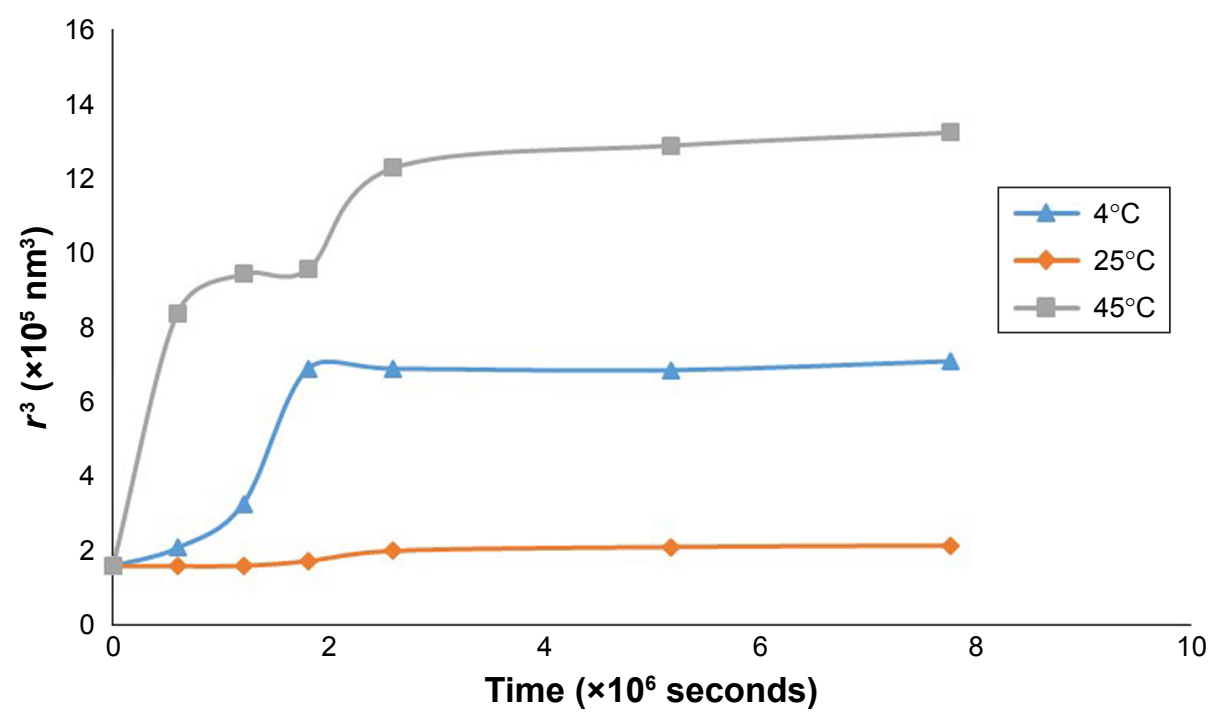

Figure 9 Graph of $r^{3}$ vs storage time (seconds). 

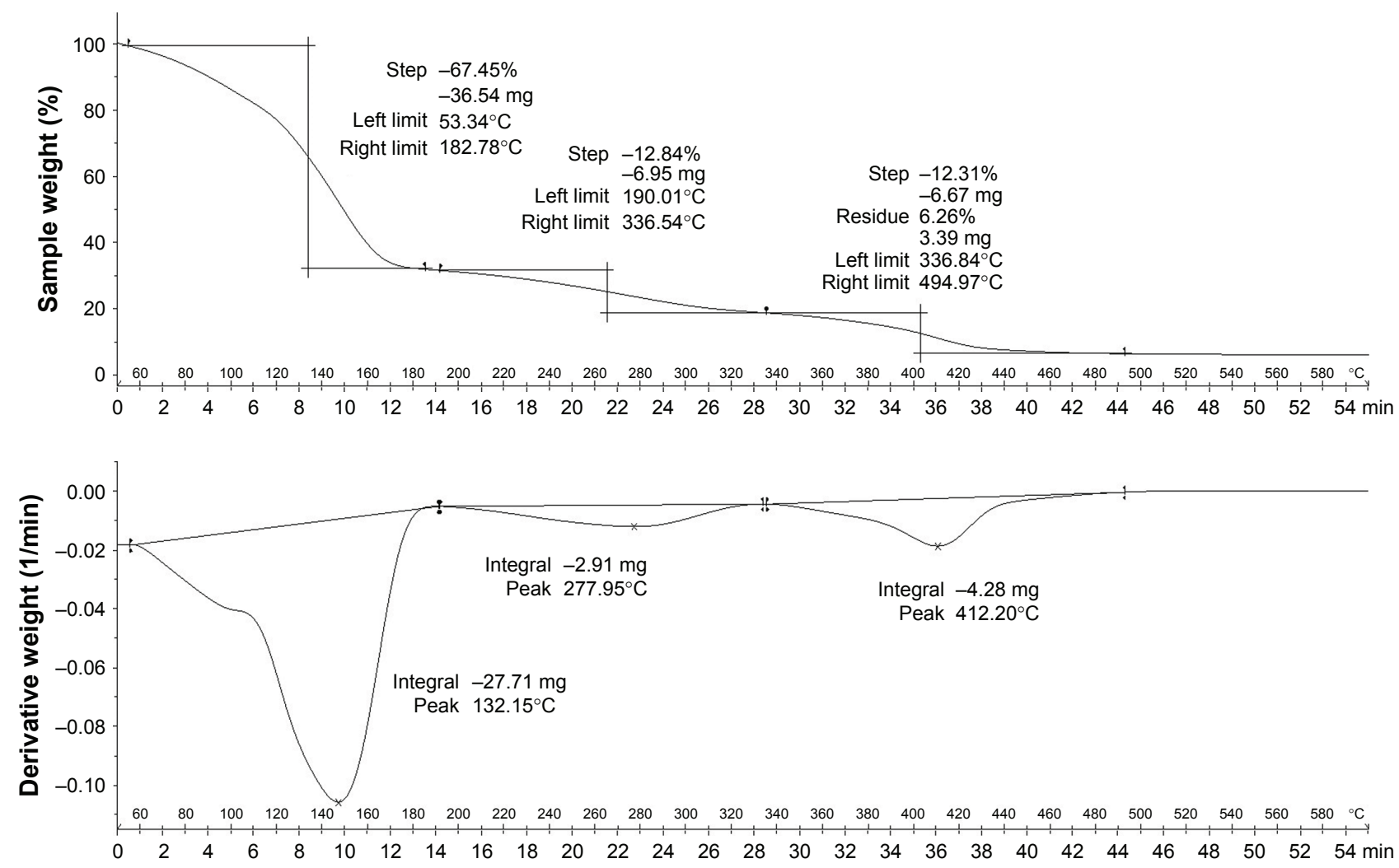

Figure 10 TGA thermogram of the optimized KMO-enriched O/W nanoemulsion.

Abbreviations: TGA, thermogravimetric analysis; KMO, kojic monooleate; O/W, oil-in-water.

\section{Conclusion}

This research indicates that an optimized composition of KMO-enriched O/W nanoemulsion using D-optimal MED is an excellent approach for topical delivery systems by combining five different variables, Tween $80, \mathrm{CO}: \mathrm{LO}$, $\mathrm{KMO}$, xanthan gum, and deionized water, for droplet size as response. ANOVA analyses demonstrated the fitness of the model with $F$-value $(2,479.87)$, a low $P$-value $(P<0.0001)$, and a nonsignificant lack of fit with high coefficient of determination $R^{2}=0.9109$. The physicochemical properties of the optimized KMO-enriched $\mathrm{O} / \mathrm{W}$ nanoemulsion displayed excellent results as a potential carrier for hyperpigmentation

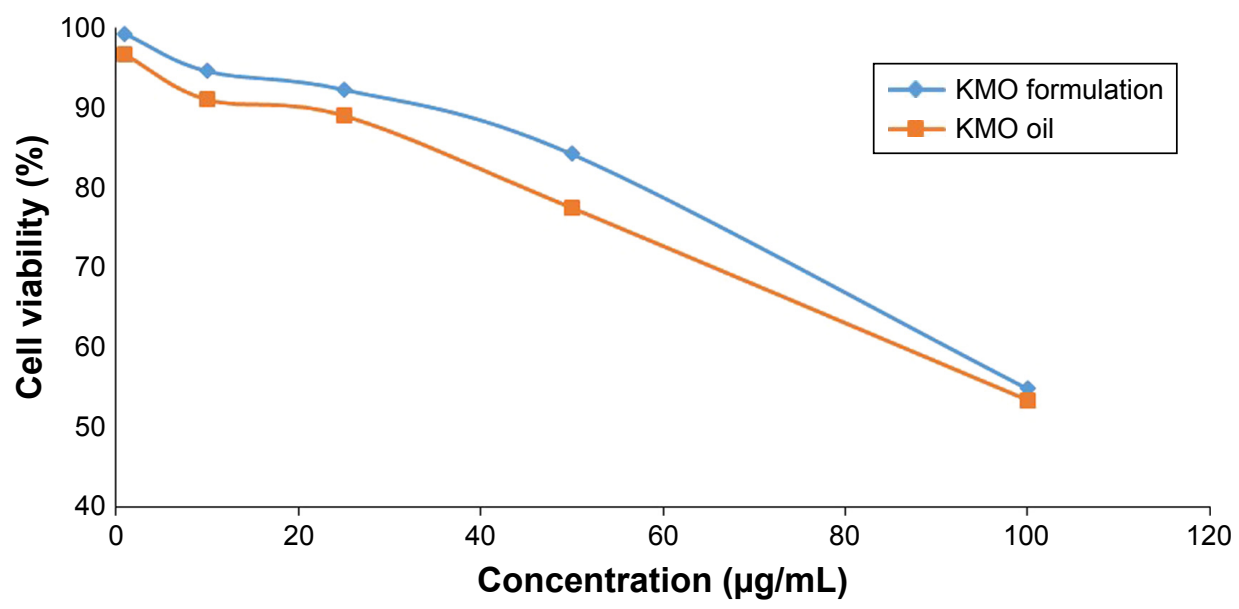

Figure II Toxicity effect of the KMO formulation and KMO oil on $3 \mathrm{~T} 3$ cells after 72 hours exposure. Abbreviation: KMO, kojic monooleate. 
treatment. The nanoemulsion displayed good stability and homogeneity against phase separation at different temperatures during 90 days of storage. The suggested storing temperature for the nanoemulsion was $4^{\circ} \mathrm{C}-25^{\circ} \mathrm{C}$ which was able to maintain the nanosized droplets over time. The nanoemulsion was affected by Ostwald ripening during storage at $45^{\circ} \mathrm{C}$ where the droplet size became larger. Under the freeze-thaw study, the nanoemulsion with $\mathrm{pH}$ $6.28 \pm 0.01$ served as the lowest condition for obtaining satisfactory stability. The in vitro cytotoxicity assay of the nanoemulsion showed that a less toxic formulation indicated safety and could be applied for cosmeceutical applications since the $\mathrm{IC}_{50}$ value of the formulation did not extend to the highest concentration of $100 \mu \mathrm{g} / \mathrm{mL}$.

\section{Acknowledgment}

The authors acknowledge Universiti Putra Malaysia for the facilities and financial assistance provided throughout this research under the Special Graduate Research Allowance.

\section{Disclosure}

The authors report no conflicts of interest in this work.

\section{References}

1. Rigopoulos D, Gregoriou S, Katsambas A. Hyperpigmentation and melasma. J Cosmet Dermatol. 2007;6(3):195-202.

2. Rendon MI, Gaviria JI. Review of skin-lightening agents. Dermatol Surg. 2005;31(7 Pt 2):886-890.

3. Uher M, Chalabala M, Cizmárik J. Kojic acid and its derivatives as potential therapeutic agents. Ceska Slov Farm. 2008;49:119-136.

4. Ashari SE, Mohamad R, Ariff A, Basri M, Salleh AB. Optimization of enzymatic synthesis of palm-based kojic acid ester using response surface methodology. J Oleo Sci. 2009;58(10):503-510.

5. Kim H, Choi J, Cho JK, Kim SY, Lee YS. Solid-phase synthesis of kojic acid-tripeptides and their tyrosinase inhibitory activity, storage stability, and toxicity. Bioorg Med Chem Lett. 2004;14(11):2843-2846.

6. Lajis AFB, Hamid M, Ariff AB. Depigmenting effect of kojic acid esters in hyperpigmented B16F1 melanoma cells. J Biomed Biotechnol. 2012;2012(4):1-9.

7. Gutiérrez JM, González C, Maestro A, Solè I, Pey CM, Nolla J. Nanoemulsions: New applications and optimization of their preparation. Curr Opin Colloid Interface Sci. 2008;13(4):245-251.

8. Chen C-S, Liu K-J, Lou Y-H, Shieh C-J. Optimisation of kojic acid monolaurate synthesis with lipase PS from Pseudomonas cepacia. J Sci Food Agric. 2002;82(6):601-605.

9. Grampurohit N, Ravikumar P, Mallya R. Microemulsions For Topical Use - A Review. Ind J Pharm Edu Res. 2011;45:100-107.

10. Borhan FP, Abd Gani SS, Shamsuddin R. The use of D-optimal mixture design in optimising okara soap formulation for stratum corneum application. ScientificWorldJournal. 2014;2014:1-8.

11. Jumbri K, Al-Haniff Rozy MF, Ashari SE, Mohamad R, Basri M, Fard Masoumi HR. Optimisation and Characterisation of LipaseCatalysed Synthesis of a Kojic Monooleate Ester in a Solvent-Free System by Response Surface Methodology. PLoS One. 2015; 10(12):e0144664-13.

12. Keng PS, Basri M, Zakaria MRS, et al. Newly synthesized palm esters for cosmetics industry. Ind Crops Prod. 2009;29(1):37-44.
13. Badea G, Lăcătuşu I, Badea N, Ott C, Meghea A. Use of various vegetable oils in designing photoprotective nanostructured formulations for UV protection and antioxidant activity. Ind Crops Prod. 2015; 67:18-24.

14. Ogunniyi DS. Castor oil: a vital industrial raw material. Bioresour Technol. 2006;97(9):1086-1091.

15. Diana MC, Steven CC, Amy BD, Amber LD. Novel-hydroxy phosphonic acids via castor oil. Ind Crops Prod. 2012;37:394-400.

16. David LC, Joseph AL, Kervin OE. Phenylpropanoid esters of lesquerella and castor oil. Ind Crops Prod. 2015;63:9-16.

17. Sinico C, Fadda AM. Vesicular carriers for dermal drug delivery. Expert Opin Drug Deliv. 2009;6(8):813-825.

18. Ammala A. Biodegradable polymers as encapsulation materials for cosmetics and personal care markets. Int J Cosmet Sci. 2013;35(2):113-124.

19. Zainol S, Basri M, Basri HB, et al. Formulation optimization of a palm-based nanoemulsion system containing levodopa. Int J Mol Sci. 2012;13(10):13049-13064.

20. Musa SH, Basri M, Fard Masoumi HR, Shamsudin N, Salim N. Enhancement of physicochemical properties of nanocolloidal carrier loaded with cyclosporine for topical treatment of psoriasis: in vitro diffusion and in vivo hydrating action. Int J Nanomedicine. 2017;12:2427-2441.

21. Krstonošić V, Dokić L, Dokić P, Dapčević T. Effects of xanthan gum on physicochemical properties and stability of corn oil-in-water emulsions stabilized by polyoxyethylene (20) sorbitan monooleate. Food Hydrocoll. 2009;23(8):2212-2218.

22. Rodd AB, Dunstan DE, Boger DV. Characterisation of xanthan gum solutions using dynamic light scattering and rheology. Carbohydr Polym. 2000;42(2):159-174.

23. Masoumi HR, Basri M, Samiun WS, Izadiyan Z, Lim CJ, Chaw JL. Enhancement of encapsulation efficiency of nanoemulsion-containing aripiprazole for the treatment of schizophrenia using mixture experimental design. Int J Nanomedicine. 2015;10:6469-6476.

24. Che Sulaiman IS, Basri M, Fard Masoumi HR, Ashari SE, Ismail M. Design and development of a nanoemulsion system containing extract of Clinacanthus nutans (L.) leaves for transdermal delivery system by D-optimal mixture design and evaluation of its physicochemical properties. RSC Adv. 2016;6(71):67378-67388.

25. Slütter B, Plapied L, Fievez V, et al. Mechanistic study of the adjuvant effect of biodegradable nanoparticles in mucosal vaccination. J Control Release. 2009;138(2):113-121.

26. Mohanraj VJ, Barnes TJ, Prestidge CA, Vellore JM, Timothy JB, Clive AP. Silica nanoparticle coated liposomes: a new type of hybrid nanocapsule for proteins. Int J Pharm. 2010;392(1-2):285-293.

27. Ngan CL, Basri M, Lye FF, et al. Comparison of Box-Behnken and central composite designs in optimization of fullerene loaded palmbased nano-emulsions for cosmeceutical application. Ind Crops Prod. 2014;59:309-317.

28. Martínez-Pla JJ, Martín-Biosca Y, Sagrado S, Villanueva-Camañas RM, Medina-Hernández MJ. Evaluation of the $\mathrm{pH}$ effect of formulations on the skin permeability of drugs by biopartitioning micellar chromatography. J Chromatogr A. 2004;1047(2):255-262.

29. Korhonen M, Niskanen H, Kiesvaara J, Yliruusi J. Determination of optimal combination of surfactants in creams using rheology measurements. Int J Pharm. 2000;197(1-2):143-151.

30. Ng SP, Lai OM, Abas F, Lim HK, Tan CP. Stability of a concentrated oil-in-water emulsion model prepared using palm olein-based diacylglycerol/virgin coconut oil blends: Effects of the rheological properties, droplet size distribution and microstructure. Food Res Int. 2014;64:919-930.

31. Samson S, Basri M, Fard Masoumi HR, Abdul Malek E, Abedi Karjiban R. An artificial neural network based analysis of factors controlling particle size in a virgin coconut oil-based nanoemulsion system containing copper peptide. PLoS One. 2016;11(7):e0157737.

32. Mat Hadzir N, Basri M, Abdul Rahman MB, Salleh AB, Raja Abdul Rahman RN, Basri H. Phase behaviour and formation of fatty acid esters nanoemulsions containing piroxicam. AAPS PharmSciTech. 2013;14(1):456-463. 
33. Chang Y, Mclandsborough L, Mcclements DJ. Fabrication, stability and efficacy of dual-component antimicrobial nanoemulsions: essential oil (thyme oil) and cationic surfactant (lauric arginate). Food Chem. 2015;172:298-304.

34. Silvestre MP, Chaiyasit W, Brannan RG, Mcclements DJ, Decker EA. Ability of surfactant headgroup size to alter lipid and antioxidant oxidation in oil-in-water emulsions. J Agric Food Chem. 2000;48(6): 2057-2061.

35. Waraho T, Mcclements DJ, Decker EA. Mechanisms of lipid oxidation in food dispersions. Trends Food Sci Technol. 2011;22(1):3-13.
36. Pongsawatmanit R, Srijunthongsiri S. Influence of xanthan gum on rheological properties and freeze-thaw stability of tapioca starch. J Food Eng. 2008;88(1):137-143.

37. Itharat A, Houghton PJ, Eno-Amooquaye E, Burke PJ, Sampson JH, Raman A. In vitro cytotoxic activity of Thai medicinal plants used traditionally to treat cancer. J Ethnopharmacol. 2004;90(1):33-38.

38. Kamoun A, Chaabouni M, Sergent M, Phan-Tan-Luu R. Mixture design applied to the formulation of hydrotropes for liquid detergents. Chemometrics and Intelligent Laboratory Systems. 2002;63(1):69-79.
International Journal of Nanomedicine

\section{Publish your work in this journal}

The International Journal of Nanomedicine is an international, peerreviewed journal focusing on the application of nanotechnology in diagnostics, therapeutics, and drug delivery systems throughout the biomedical field. This journal is indexed on PubMed Central, MedLine, CAS, SciSearch $®$, Current Contents $® /$ Clinical Medicine,

\section{Dovepress}

Journal Citation Reports/Science Edition, EMBase, Scopus and the Elsevier Bibliographic databases. The manuscript management system is completely online and includes a very quick and fair peer-review system, which is all easy to use. Visit http://www.dovepress.com/ testimonials.php to read real quotes from published authors.

Submit your manuscript here: http://www.dovepress.com/international-journal-of-nanomedicine-journal 